\title{
Research on the Situation and Countermeasure of the Inventory of Real Estate in Xi'an City
}

\section{Furong Feng}

Xi'an Peihua University, Xi'an, Shaanxi, China, 710125

\author{
Keywords: Situation, Countermeasure, the Inventory of Real Estate, Xi'an City
}

\begin{abstract}
The current national real estate market presents a "total excess, lack of start, lack of demand," the overall characteristics, and in the process of inventory to form a "differentiation intensified, highlight the risk" and other industry characteristics. This paper analyzes the process of real estate in Xi'an to determine the real estate industry still has a large space for development, as long as the follow-up to maintain a new scale at a moderate level, the real estate inventory size will gradually decline, the industry outlook is still relatively stable. This paper suggests that the real estate enterprises from the transformation and financial institutions to boost the two aspects to speed up the inventory process of real estate in Xi'an.
\end{abstract}

\section{Introduction}

At present, China is in the process of continuous optimization and transformation of economic structure and layout, the economic development is experiencing a significant pain period, GDP growth from the end of 2012 continued to decline, the economic development of three carriages are weak, import and export by the international constraints, domestic consumption sluggish, investment performance in the doldrums. In 2016, the government put forward the five tasks of "to produce capacity, to inventory, reduce costs, to resolve financial risks and expand effective supply", opening the process of Chinese supply side reform.

In China, due to the current financial market constraints system, real estate financing in addition to its own funds, to indirect financing, leading to real estate development financing over-reliance on commercial bank loans, and such as financing, trust financing and other financial means accounted for a small proportion which makes the real estate investment market risk and financing credit risk is highly concentrated in the commercial banks, while the high real estate development brought about by the high profits of commercial banks to boost the real estate credit growth. Once the real estate rising trend reversal, housing crisis is extremely easy through the public consumption and investment behavior passed to the financial system, due to the uneven development of the real estate area characteristics, easy to cause the real estate bubble in the regional real estate market accumulation, leading to regional financial risk spread and proliferation, thus endangering the prosperity and development of regional economy. Since 2003, the Chinese government has adopted a series of macro-control policies and measures, has six times lower interest rates, more than a dozen times to raise the deposit reserve ratio to control the real estate investment "irrational frenzy." Xi'an as the western development of the forward position, but also promoted to the emerging first-tier cities, the market economy than the north of Guangzhou and Shenzhen and other first-tier cities are still no small gap between the real estate price fluctuations in Xi'an on the impact of financial instability, for other emerging line Urban and second-tier cities have important reference value, and for the current stage of "to the production capacity, to inventory, reduce costs, to resolve financial risks, expand the effective supply of" five tasks "to inventory, to resolve financial risks" two tasks with reality Guiding significance, at the same time on the development of real estate finance in Shaanxi Province and even the western region has important significance. 


\section{The Characteristics of the Real Estate Market in Xi'an}

The Real Estate Turnover Hit A New High, Housing Price is Basically Stable. The industry has entered the adjustment period in 2015, the Xi'an housing market with interest rate cuts, down the standard, the new nine and the new deal and other favorable policies continue to introduce the market gradually showed a warming trend, 2015 commodity real estate market turnover increased by $19.8 \%$ housing prices remained stable, short-term inventory has been effectively mitigated.

The price of Xi'an real estate transaction is 6770 yuan / square meter, up $0.5 \%$ year on year, with the basic flat in 2014. In the industry downturn trend continues to increase the status quo, the government's favorable policies continue to introduce, developers take a variety of marketing tools and a variety of preferential policies, from the overall situation throughout the year, the real estate market rebound trend is significant.

From the single-month price level, the average price of real estate in February is relatively high, at 7047 yuan / square meter, in July fell to the lowest level of single-month transaction price of 6552 yuan / square meter, the second half showed a rising trend. In December rose to 7056 yuan / square meter, up 3.0\% year on year, the highest monthly price level for the month.

The Demand Release, Inventory Pressure Has Slowed. 2015, benefiting from the endless favorable policies, the market pick up the situation is obvious, Xi'an commercial real estate sales area hit a record high, closing an area of 14.283 million square meters, an increase of $19.8 \%$, the new listing area of about 12,489,000 square meters, down $5.6 \%$ year on year, Xi'an real estate market commodity real estate sales ratio from 0.9 in 2014 rose to 1.1, the data show that the real estate market inventory pressure has been eased. The structure of the transaction is that the rigid demand is still the mainstream of the market, and the improvement of the demand is more obvious.

\section{The Financial Risk in the Process of Inventory of Real Estate in Xi'an City}

Xi'an commercial housing market as of the end of 2015 inventory of 39.61111 million square meters to the cycle of 27 months, Xi'an commercial real estate as of the end of 2015 inventory of 18.8542 million square meters, to the cycle of 16 months, the inventory ranked third in the city, Higher than its inventory is Shenyang and Tianjin, follow-up to the pressure is very large.

The economic kinetic energy is not enough to go inventory. Most of the second-tier cities inventory level and the city's economic momentum should be upside down, with the policy, with time to inventory should be gradually digested. But the current problem in Xi'an is the economic kinetic energy is mainly reflected in the serious imbalance in industrial structure. Statistics released from the Xi'an Statistical Yearbook, the industry accounted for not small, but the economic contribution is not ideal. First, because there is no leading enterprises; Second, some military enterprises in Xi'an and the central enterprises, tax is completely out of control; Third, Xi'an industrial chain extension of small, more lack of unified planning, each industrial park repeat high. Xi'an's advantage is culture, tourism and technology, but the development of real estate industry can rely on the tertiary industry pull it? Fixed asset investment by the service industry, which is obviously not possible.

The population flow is not enough to drive to inventory. Nearly five years, the net population of Xi'an population of 190,000 (also said that the data is 59 million), the country's penultimate. Compared to Shanghai, the net inflow of population in the past five years is 27 times that of Xi'an. At the same time, Yulin City, Shaanxi Province, a year net population loss of more than 200,000.

The financing costs are too high. Xi'an developers to the south private equity costs more than $20 \%$, even the World Union of these national institutions, financing costs more than $12 \%$. This means that if the developer cannot sell a house within a year, it is equivalent to $20 \%$ price reduction. Although the government of Xi'an is encourage developers to cut prices, but this is equal to the enterprise erosion, so most developers are waiting for the government to save the city.

Beijing, Shanghai, these first-tier cities account opening, population mobility, capital flows and industrial upgrading, the real estate industry is not the main business. "To inventory" the biggest 
pressure from the Xi'an line of 1.5 and second-tier cities. Industry is weak, the economy is weak, the population is weak, the property market is high and the local debt is high, which causes the real estate industry in Xi'an to "inventory" is very difficult, this process derives a series of risks, bear the brunt impact to the financial system , easily lead to financial instability.

\section{The Countermeasures and Suggestions to Speed up the Inventory of Real Estate}

Merger and Reorganization of Inventory, Optimize the Real Estate Industry Pattern. Many real estate enterprises because of the smaller scale, higher development costs, coupled with no brand value-added products, often due to poor sales and fall into financial difficulties. Through the mergers and acquisitions of real estate enterprises, part of the small real estate companies take the initiative to cooperate with large housing prices, large-scale housing prices will continue to expand, small companies do not necessarily need to reduce the way through the price of existing inventory, if you need to cut prices can be achieved through large-scale development to reduce costs and expand the price of space. Listed housing prices can be operated through capital operation, such as large-scale listing of housing prices through the acquisition of equity or project to do the market value of large, in the medical, tourism and other areas of cross-border mergers and acquisitions. Through the merger and reorganization, with minimal cost to revitalize the stock to achieve the market survival of the fittest, to enhance industry concentration, optimize the industry structure, to encourage real estate enterprises bigger and stronger. And thus enhance the overall development and operation of the industry level to achieve the real estate market supply and demand of efficient matching.

The Subdivision Areas of Real Estate Business Transformation Meets the Diversification. Demand to solve the real estate industry homogenization of serious problems and real estate companies can actively seek business transformation to seek new opportunities for development. On the one hand, real estate enterprises in the internal re-integration of resources at the same time, to find new resources to absorb and supplement, and other industries, such as tourism, health care, culture and the Internet industry, cross-border integration to achieve the expansion of business segments. It can be grafted by the real estate business development potential of the industry resources, the development of pension real estate, tourism real estate, medical real estate, cultural real estate, in order to achieve effective integration of resources to achieve complementary advantages, resource sharing, mutual benefit and win - win objective. On the other hand, through the breakdown of the target market, the product transformation, release or create market demand, for the different needs of the characteristics of the design characteristics of products, matching segmented target customer base. Some of the leading enterprises in the industry experience for many real estate companies to provide reference. Such as Vanke launched the rice apartment, for the work of college students and white-collar groups want to live in the convenience of the city center, but the economic capacity and cannot afford the demand for large housing.

The Bank Strengthen Credit Support and Take Participation in Housing Provident Fund Assets. Brokers can play an active role in real estate to inventory. It can take the initiative and flexible use of a variety of means to participate in them, such as the provision of credit financing, to the provident fund center loans to solve the problem of insufficient funds for provident fund loans to broaden the sources of individual housing loans to shorten the individual housing loans lending approval period. It can play a certain degree of flexibility, in the policy allowed to determine the scope of their down payment. In addition to traditional commercial credit, banks can also strengthen cooperation with other financial institutions such as trusts and securities to provide integrated financial services for "real estate banks + investment banks" for real estate enterprises. All kinds of financial institutions can also cooperate with the provident fund management center around the issue of housing provident fund asset securitization products, both can make an inventory of provident fund loans to improve the loan turnover rate, ease the liquidity center of the status quo, but also help reduce the cost of housing buyers go to inventory.

Play an Effective Support Role of Financial Institutions to Boost the Real Estate Enterprises to the Combination of Light and Heavy Assets Model. At present, most of the real 
estate business is also basically in the heavy asset stage, commercial real estate is to earn the development of profits, asset appreciation income and rental income, and light assets under the main business by professional companies to take care of. But the current real estate market in China, whether residential or commercial real estate, have entered the stock room era, housing prices are facing the dual pressures of capital and operation. Real estate enterprises should pay more attention to enhance the value of the property and hold business, not only have a professional asset management, but also the use of advanced financial instruments to transform the stock of commercial real estate, enhance its value. On the one hand, through the real estate finance to solve the financial problems, the use of real estate trusts or real estate funds way to run real estate projects, help enterprises to diversify the risk of individual projects to improve the rate of return. On the other hand, real estate finance can be used to transform inefficient properties. Financial institutions to play the role of financial support to build real estate financial industry chain, the flexible use of "equity + debt", "stock + incremental" and other investment and real estate finance asset acquisition, real estate mortgage loans, real estate trusts, real estate investment funds, assets Securitization and other means to boost the real estate business to the combination of light and heavy assets model to achieve from the real estate development to provide integrated operations services transformation.

\section{Conclusion}

With the rapid development of Chinese new urbanization process, the healthy development of the real estate industry will become Chinese largest domestic demand and development of new impetus. Real estate to inventory as one of the top ten structural reforms in 2016, for the stability of economic growth and prevention of financial risks are of great significance. This paper suggests that the real estate enterprises from the transformation and financial institutions to boost the two aspects to speed up the process of real estate in Xi'an to inventory.

\section{Acknowledgements}

Fund Project: 2017 Annual Xi'an Social Science Planning Fund Peihua Project, Project Name: The path study on the inventory of real estate of Xi'an commercial housing based on the reform of supply side (project number: 17PH14)

\section{References}

[1] Wu Nianru, Yang Haiping.Prevention and Governance of Economic and Financial Risk Infection - Based on the Analysis of Balance Sheet[J]. Southwest Finance. 2016 (02)

[2] Shen Yue, Guo Peili. Income, housing prices and financial stability - from the heterogeneous panel threshold model analysis [J]. Economic Science. 2015 (06)

[3] Zhao Yuan. House price volatility, credit structure and financial stability - based on the 1998 2012 data empirical analysis [J]. Wuhan Finance. 2015 (12)

[4] Shen Yue, Guo Peili. The asymmetric action mechanism of house price shock on financial stability[J]. Journal of Xi'an Jiaotong University (Social Science Edition) 2015 (06)

[5] Huang Dechun, Wang Bo, Guo Shudong. China 1998 - 2013 financial system vulnerability assessment[J]. Journal of Hohai University (Philosophy and Social Sciences) 2015 (05) 